\title{
Social origins, academic strength of school curriculum and access to selective higher education institutions: Evidence from Scotland and the USA
}

\author{
Adriana Duta ${ }^{1} \cdot$ Brian An $^{2} \cdot$ Cristina Iannelli ${ }^{1}$
}

Published online: 17 July 2017

(C) The Author(s) 2017. This article is an open access publication

\begin{abstract}
This paper analyses the role that different components of the academic strength of the secondary-school curriculum (i.e. number, subjects and grades of advanced academic courses) play in explaining social origin differences in access to prestigious universities (but also to other higher education institutions) in Scotland and the USA. A central aim of the paper is to investigate whether the mechanism behind the studied patterns of inequality differs depending on the characteristics of each educational system. Our results show pronounced social class gaps in entering top higher education institutions in both Scotland and the USA. Academic curriculum plays an important role in explaining these social class differences in both countries. However, while in Scotland type of subjects taken at an advanced level is the strongest mediator for the identified social class differences, in the USA, number of advanced subjects is the strongest. Moreover, taking into account the three academic components combined entirely explains the social class differences in Scotland. Considerable inequalities which are not explained by the strength of academic curriculum remain in the USA.
\end{abstract}

Keywords Social inequality $\cdot$ Entry to higher education $\cdot$ Selective universities $\cdot$ Academic school curriculum $\cdot$ Scotland $\cdot$ USA

\section{Introduction}

Participation in secondary and tertiary education has increased considerably in modern societies over the last decades. However, as participation in education increases, qualitative

Electronic supplementary material The online version of this article (doi:10.1007/s10734-017-0166-5) contains supplementary material, which is available to authorized users.

Adriana Duta

Adriana.Duta@ed.ac.uk

1 Moray House School of Education, University of Edinburgh, Edinburgh, UK

2 Educational Policy and Leadership Studies, University of Iowa, Iowa City, IA, USA 
distinctions, such as the type of qualification achieved and the prestige of the institution attended, may become more salient in the reproduction of social inequalities in education (Lucas 2001). These qualitative distinctions are important as they translate into further inequalities in the labour market (Jacob et al. 2015).

Although extensive literature exists on the persistence of social class inequalities in entry to higher education (HE) (e.g. Shavit et al. 2007), fewer studies have investigated the factors that explain social inequalities in entering more selective universities. School-related factors have been suggested to be among the key explanations for horizontal stratification in HE (Gerber and Cheung 2008) and some studies have empirically tested the extent to which different school factors (e.g. attainment and subject choice) mediate inequalities in entering more prestigious universities (Boliver 2013; Iannelli et al. 2016; Sullivan et al. 2014). However, none of these studies have systematically assessed the different ways in which academic curriculum explains social inequalities in entering more selective HE institutions (the lone exception is Schührer et al. 2016). Our paper addresses this gap by investigating the relative importance of different dimensions measuring the academic strength of secondary school curricula - that is the number and type of academic courses taken, and performance in these courses - in reproducing social class inequalities in entry into selective HE institutions in Scotland and the USA.

Our paper addresses three research questions. (1) To what extent is parental social class associated with access to more selective universities in Scotland and the USA? (2) Do the number, types and grades of advanced academic courses explain social class differences in access to selective universities in ways that vary between Scotland the USA? (3) Does the academic strength of curriculum taken in secondary school fully explain these social class differences in the two countries?

The comparison between Scotland and the USA sheds light on whether and how the mechanisms behind the social class differentiation in entering prestigious HE institutions differ depending on the characteristics of the education system. Past cross-national comparisons between the UK and the USA have been particularly instructive in uncovering different internal mechanisms of social reproduction of inequalities in these two countries which share many societal aspects (see for example the seminal works of Kerckhoff 2001; Turner 1960). The aspects which are most relevant to our work (which focuses on Scotland rather than the wider UK) are those related to the structure and content of the education system. Thus, the USA and Scotland are similar with respect to the (a) low stratification of curriculum in secondary education (Allmendinger 1989), (b) pronounced hierarchy of tertiary institutions (Shavit et al. 2007) and (c) importance of curriculum studied in secondary school for entry into selective universities.

The USA, however, differs in three important ways from Scotland: (a) a fee is charged for assessment of performance in Advanced Placement (AP) courses (college-preparatory courses) whereas no such fee is charged to students who take Highers or Advanced Highers (the final upper-secondary school examinations) in Scotland; (b) tertiary institutions charge tuition fees (in general, the more prestigious the university, the higher the tuition fee) while universities do not charge tuition fees in Scotland, regardless of the prestige of the university; and (c) entry into HE is not based on specific disciplines as in the case of Scotland where students apply to both a university and a college major. These differences are likely to shape the way in which social class inequalities at entry to various types of HE institutions are reproduced in the two countries. On the one hand, given the costs associated with studying at prestigious universities in the USA, we expect that differences in the academic strength of curriculum studied at school 
will explain less of the class-of-origin effect in the USA than in Scotland because economic factors are likely to play a more important role in the USA. On the other hand, since prospective students in the USA are not required to choose their field of study at the time of their HE application, we expect that the type of advanced academic subjects taken at school plays a weaker role in mediating social inequalities relative to grades and number of advanced subjects.

In both the USA and Scotland, selection of school subjects is a crucial decision that determines students' chances of entering prestigious universities. In the USA, strength of curriculum is an important differentiating factor considered by many universities, even more important than admission test scores and students' overall grades (Clinedinst 2015). Similarly, in Scotland (and more generally in the UK), the Russell Group (2016) universities - the more selective and research-intensive universities - have highlighted eight subjects as facilitating entry into their institutions: English Literature, History, Modern and Classical Languages, Maths, Physics, Biology, Chemistry, and Geography.

However, research in both countries has shown that access to a rigorous academic curriculum is stratified by parental social class: students from lower social backgrounds are less likely to take academic subjects than students from more advantaged social backgrounds. Different degrees of information and advice that students from different social origins have access to, as well as different opportunity structures, play a role in this. Thus, flexibility in curriculum choices in Scotland would tend to advantage students from higher social classes because their families are more familiar with the education system and have a better understanding of the role that subject choices play for entering selective HE institutions (Iannelli et al. 2016). Moreover, structural factors, such as schools' provision of advanced-level subjects, may also reinforce social inequalities, with schools in economically disadvantaged areas not offering these subjects at all or providing only a limited number of subjects from which to choose (Klugman 2013). Nevertheless, evidence from the USA suggests that socioeconomic inequality persists in the uptake of AP courses, even in schools with a high provision of these courses (Handwerk et al. 2008).

Due to lack of data, in our study we are unable to investigate the role of school provision and guidance on the take-up of advanced-level courses in academic subjects. However, the richness of information on curriculum studied in secondary school, HE institutions entered and school leavers' social background characteristics contained in the Scottish School Leavers Surveys and the Education Longitudinal Study for the USA allows us to compare the importance of various components of academic curriculum in explaining social inequalities at entry into different HE institutions in the two countries.

\section{Literature review}

In Scotland and the USA, HE expansion has been accompanied by differentiation of HE institutions (Arum et al. 2007). In Scotland, Iannelli et al. (2011) found that, at the time in which Scottish HE expanded most, a process of diversion emerged where these new universities catered to less privileged students who would have otherwise not received a universitylevel education, while elite universities continued to attract individuals from privileged backgrounds. Similarly, Alon and Tienda (2007) found that in the USA, expansion was accompanied by increasing enrolments in lower-status institutions, such as non-selective 4year institutions and community colleges. Moreover, social stratification by parental education 
remained, with students with more educated parents significantly more likely to attend 4-year institutions (including the most prestigious ones) and students with less educated parents significantly more likely to attend 2-year institutions.

Various studies have analysed potential factors that explain the association between social class background and access to selective HE institutions. Some have stressed the role of prior educational attainment (Gerber and Cheung 2008; Jerrim et al. 2015), while others have pointed out a complex interplay of individual, family and contextual factors, such as level of aspirations, confidence, knowledge of the education system and the socioeconomic context of schools or neighbourhoods (Lareau 2011; Massey et al. 2003; Reay et al. 2005).

In the UK, analyses based on large-scale quantitative data have shown that the social class gap in access to selective HE institutions is almost fully explained by differences in cognitive abilities in childhood and teenagehood (Sullivan et al. 2014) or by a combination of grades and types of subjects studied at school (Boliver 2013; Iannelli et al. 2016). In the USA, students of lower socioeconomic status (SES) have increased their academic credentials over time, but so has their high-SES counterparts, making stratification in HE entry relatively unchanged (Bastedo and Jaquette 2011). Even among the academically talented, differences between where students apply and eventually enrol exist based on social class. In her study of high school valedictorians - typically defined as the top academic student of a class - Radford (2013) found that $75 \%$ of high-SES valedictorians considered academic reputation/prestige of institution as among the top five college characteristics in their decision of where to enrol as compared to $59 \%$ of low-SES valedictorians.

Regarding the importance of secondary school curriculum, Boliver (2013) showed that facilitating subjects in A levels were important for entering the UK Russell Group universities, regardless of the obtained grades. In a comparative study between Scotland and Ireland, Iannelli et al. (2016) found that in Scotland-where curriculum choice is flexible and universities can set their criteria for student selection - the subjects studied at secondary school represent an important mechanism through which social class inequalities in HE entry emerge. However, this was less the case in Ireland where secondary school curriculum is more standardized and subject choice matters less for HE admission; instead, attainment was a stronger mediator. Our study extends Iannelli et al.'s (2016) work by explicitly testing qualitative and quantitative aspects of academic curriculum rigour in explaining social class inequalities in entry into prestigious HE institutions in two countries with different $\mathrm{HE}$ education systems.

\section{Education systems in Scotland and the USA}

Scotland There are four types of institution in the Scottish higher education sector. The four ancient universities-Aberdeen, Edinburgh, Glasgow and St. Andrews-founded in the fifteenth and sixteenth centuries, mainly taught a broad curriculum including the main branches of academic study. In the 1960s, a period of HE expansion in the UK, four old universities were created: Dundee, Heriot-Watt, Stirling and Strathclyde. The subject coverage of these universities was not as broad as that of the ancient universities. The third HE sector, generally referred to as new universities (also known as post-92 universities), emerged in 1992, at the time in which polytechnic colleges were given higher education status, and five of them-Abertay, Caledonian, Napier, Paisley (now merged in the University of the West of Scotland) and Robert Gordon-became universities. The fourth sector consists of further education (FE) colleges which were set up mainly in the 1950s as vocational colleges. Their 
higher education courses are mainly 1- and 2-year sub-degree qualifications. An advantage for students in Scotland, as compared to students in the USA, is that they do not pay tuition fees if they attend a Scottish university (regardless of the university's prestige). ${ }^{1}$

In the final 2 years of secondary school, students take subject-specific examinations, Highers and Advanced Highers, which enable university entry. However, there are no compulsory subjects that students must study as well as no specific requirements in the number of subjects that they must sit for their final secondary school examinations. This leads to significant differences in the number, types and levels of exams students take.

Although in Scotland, as in the rest of the UK, there are no defined prerequisites regarding the number and nature of studies undertaken at secondary school, universities have some expectations about them. Generally, universities expect prospective candidates to achieve between three and five Highers (Johnson and Hayward 2008). However, selective universities have generally higher entry requirements in terms of number of Highers, grades and types of subjects studied. Also, although the official requirements may seem comparable to less selective institutions, in practice, the competition for entering the most selective institutions is fierce, making the actual criteria for admission to selective institutions more rigorous than officially stated. Moreover, to finance the system of free tuition, the Scottish Government has imposed a cap on students' places and reduced their maintenance grants, which has made it more difficult for universities to increase the number of low-SES students.

USA In the USA, post-secondary schools comprise 4-year institutions (42\%), 2-year colleges $(30 \%)$ or institutions that are less than 2 years $(28 \%)$ (Integrated Postsecondary Education Data System 2014). (All results using the 2014 IPEDS data were calculated by the authors.) Fouryear institutions typically offer baccalaureate (i.e. bachelor's) degrees, whereas 2-year colleges typically offer associate's degrees and certificates. Institutions that are less than 2 years offer non-degree sub-baccalaureate certificates. Students typically apply for admissions to colleges. However, most institutions that are 2 years or less (92\%) are open admissions, meaning that they will accept any student who applies. By contrast, only $29 \%$ of 4-year institutions are open admissions (IPEDS 2014). HE institutions in the USA charge tuition fees. However, these fees tend to be higher in private institutions than in public institutions, in 4-year institutions than in 2-year institutions and in more prestigious institutions than in less prestigious institutions (Roksa et al. 2007).

Admissions to a 4-year institution typically is determined by reference to several criteria, such as students' GPAs, high school course work, recommendations and standardized test scores (e.g. SATs or ACTs). In 2014, the percentage of 4-year institutions that required or recommended the following criteria for admissions were as follows: high school coursework (97\%), high school GPA (87\%), standardized test scores (83\%), recommendations (76\%) and school rank (62\%) (IPEDS 2014). Correspondingly, admission offices identified grades in college-preparatory courses, strength of curriculum and standardized admission test scores as the three top factors in their admission decisions (Clinedinst 2015).

Most public high schools provide advanced courses, such as Honors, AP and International Baccalaureate (IB). Approximately $70 \%$ of public high schools have students enrolled in AP or IB courses. The College Board administers the AP program and offers 36 courses across six

\footnotetext{
${ }^{1}$ The Bill which introduced free tuition fees was approved in February 2008. Before then, HE students were required to pay a graduate endowment after graduation. The cohort of school leavers we will analyse in this study graduated at the time of the abolition of the graduate endowment.
} 
general subjects (Arts, English, History and Social Science, Math and Computer Science, Sciences and World Languages and Cultures) (College Board 2016). The intent of the AP and IB programmes is to provide students with a college-level learning experience. Moreover, students who successfully pass an AP exam, typically a score of 3 or higher, often receive college credit or placement into advanced courses.

\section{Data and methods}

For the analysis in Scotland, we used data from the 2002 Scottish School-Leavers' Survey, a nationally representative longitudinal survey of young people who attended S4 during the 2001-2002 academic year. We also used data from the follow-up surveys which were conducted first in 2003 when respondents were aged 16-17 years, and second in 2005 when they were aged 18-19 years. The initial sample sizes for these two follow-ups were 5088 and 3245 , respectively. Given that the focus of our study is to investigate selectivity of the HE institutions, we built our sample based on the second follow-up (2 years after leaving upper secondary education). After selecting those who enrolled in tertiary education, the sample reduced to 1565 respondents and it further reduced to 1499 after removing cases with missing data.

For the US analysis, we used data from the Education Longitudinal Study of 2002 (ELS:2002), a nationally representative study of 10th grade students in 2002. Students were followed in 2004 (when they were in the 12th grade), 2006 (2 years after high school) and 2012 (8 years after high school). ELS:2002 investigators also conducted a transcript study in 2005 (secondary school) and again in 2013 (post-secondary school). For our analysis, we used the base year (2002), first follow-up (2004) and second follow-up (2006) survey as well as the secondary school transcript study. The ELS:2002 data initially contained 16,200 students. ${ }^{2} \mathrm{We}$ restricted the sample to those with a high school transcript, which led to 14,810 students. We selected students who attended a post-secondary school by the second follow-up, further reducing the sample to 10,970 students. Finally, we performed listwise deletion, ${ }^{3}$ resulting in an analytical sample of 8350 students.

\section{Selectivity of the HE institution}

The dependent variable was the selectivity of the HE institution where a student enrols. In Scotland, we distinguished four categories of HE institutions, according to the historical developments highlighted above: (1) 'ancient' universities, (2) 'old' universities, (3) 'new' universities) and (4) further education (FE) colleges. As a test, we grouped Scottish universities based on quartiles constructed on the average Universities and Colleges Admissions Service (UCAS) score at entry, but this construction led to an almost identical grouping of institutions.

\footnotetext{
${ }^{2}$ We rounded all numbers reported for ELS:2002 to the nearest 10 as required by the National Center for Education Statistics for use of their data.

${ }^{3}$ While for Scotland, the percentage of the excluded cases due to missing data was under $1 \%$, for the USA, this was $20.5 \%$. Robustness checks for the USA show that using multiple imputation to deal with the missing data does not change the overall narrative of our results apart from indicating a potential slight underestimation of the service-intermediate class gap.
} 
To measure college selectivity in the USA, we used the College Admissions Selector from the Barron's Profiles of American Colleges, which captures the level of competition-based on grades, class rank, etc. - a student might face when applying to a given college or university (Barron's Educational Series 2002). Social scientists have commonly used the Selector as a measure of college selectivity (Alon and Tienda 2007; An 2010; Brand and Halaby 2006). The Selector has six categories of admission competitiveness and does not consider 2-year colleges. To increase statistical power and to make the analysis more compatible with the Scottish context, we collapsed the six categories into three categories and added 2-year colleges as an additional category, leading to the following classifications: (1) 'highly competitive and most competitive', (2) 'competitive and very competitive', (3) 'noncompetitive and less competitive' and (4) 2-year colleges.

\section{Social class}

Social class of origin was measured using three class categories: service class, intermediate class and working class. In Scotland, this was coded according to the European Socioeconomic Classification (Rose and Harrison 2010) using SOC-2000 occupational codes. These were then grouped into (1) service class, including higher and lower managerial and professional occupations (ESeC 1\&2); (2) intermediate class, including intermediate occupations, small employers and self-employed (ESeC 3-5); and (3) working class, comprising lower supervisors and technicians, lower services, sales and clerical occupations, lower technical occupations and routine occupations (ESeC 6-9). However, in the USA, social class was based on a list of 17 categories that best describe respondents' occupations. We made efforts to harmonize the two classifications by carefully grouping the USA occupations according to the compressed $\mathrm{ESeC}$ categories. ${ }^{4}$ Both definitions adopted the 'dominance principle' which takes the parent with the highest social class as the indicator of one's social class (Erikson 1984).

\section{Academic strength of school curriculum}

We conceptualized the academic strength of secondary school curriculum as three dimensions of academic rigour which are important to college/university admissions. ${ }^{5}$ First, we considered the number of academic subjects (i.e. non-vocational subjects) taken at an advanced/university preparatory level (Highers and Advanced Highers in Scotland and AP/IB/Honors in the USA). Second, we included the type of academic subjects taken at an advanced level. ${ }^{6}$ More specifically, we included all academic subjects that could be taken at an advanced/university preparatory level: English, Foreign Languages, Mathematics, Biology, Chemistry, Physics, Geography, History, Other Sciences, Arts and Social Sciences. Finally, we included the obtained grades for the academic advanced courses studied. In Scotland, this was the sum

\footnotetext{
${ }^{4}$ More details about the social class grouping are provided in Online Resource 1.

${ }^{5}$ This conceptualization is not meant to reflect our subjective view on what represents a 'good education' but is rather meant to help us to test empirically some of the key existing criteria for entry to HE in the two education systems under study. A discussion about the adequacy of these criteria is beyond the scope of the paper.

${ }^{6}$ While for Scotland the subject dummies indicate that the student has obtained at least a pass in that particular subject, for the USA the subject dummies measure whether the student has studied that particular subject. This acknowledges existing differences in the two education systems. While passing subject-specific examinations is essential for entering HE in Scotland, in the USA, participating in AP/IB/Honors courses (which are demanding and optional) enhances a student's chance of entering selective institutions.
} 
of the UCAS point scores obtained for the academic subjects taken at Higher and Advanced Higher level. The score takes into account the subjects' level of difficulty, with subjects taken at Advanced Higher level scoring the highest (i.e. the corresponding UCAS scores for A, B and $\mathrm{C}$ grades for Advanced Highers are 120, 100 and 80, respectively, while for Highers these are 72, 60 and 48, respectively). ${ }^{7}$ In the USA, students' academic GPAs was constructed based on the cumulative grade point average of all courses taken from $\mathrm{AP} / \mathrm{IB} / \mathrm{Honors}$. This was a continuous measure on a four-point scale, where a 0 represents an ' $F$ ' letter grade and a 4 represents an 'A' letter grade.

\section{Control variables: sociodemographic indicators}

We included several sociodemographic indicators, such as race, gender and family background. In the USA, we measured race as Black, Asian, Latino and other race/ethnicity with White as the reference category. However, in Scotland the sample was not sufficiently ethnically diverse, hence, we only controlled for a broad nationality variable with three categories: Scottish, British and Non-British, with Scottish being the reference category. Gender was defined as a binary indicator coded 1 for females and 0 for males. Regarding the additional family background characteristics, family structure was coded using four categories: single parent, stepparent and other family compositions with two-parent biological families as the omitted category. We further included the number of siblings living in the same household as a categorical variable with four categories: no siblings (reference category), one sibling, two siblings and three or more siblings. ${ }^{8}$

\section{Methods}

We used multinomial logistic regression to address our research questions. However, to facilitate interpretation of the results and allow comparison across models, we report average marginal effects (AMEs), which convert the multinomial log-odds to the probability scale. This approach overcomes the issue of rescaling to which the log-odds are subject due to the bias introduced by the changing underlying unobserved heterogeneity when the model or the sample composition changes (Mood 2010).

We included five separate models for Scotland and the USA, which present the probability of entering each of the four HE institution types. Model 1 (M1) shows the effects of parental social class while controlling for sociodemographic and other family background variables described above. The next three models build on M1 and introduce one measure of academic strength at a time while leaving out the other two measures of academic strength. This approach tests the role that each measure of academic strength has in explaining the observed inequalities by parental social class shown in M1. Comparing the results of Scotland and the USA reveals whether the considered academic components act in the same way in explaining the social class gap in the two countries or whether certain components are stronger in one country than in the other. This tests whether the mechanism behind the social class gaps in access to selective or less selective HE institutions is specific to each education system.

\footnotetext{
${ }^{7}$ In cases where students took both a Higher and an Advanced Higher in the same subject, only the score obtained for the Advanced Higher was considered; this is in line with the methodology followed by UCAS.

${ }^{8}$ Table A1 (Online Resource 2) shows a list of univariate descriptive statistics for all variables used in this study.
} 
Therefore, building on M1, M2 adds the number of academic subjects taken at an advanced level, M3 includes the type of subjects taken at an advanced level and M4 introduces an average measure of the grades obtained for the advanced academic subjects taken. Finally, M5 includes all the academic components together testing whether social class gaps persist after accounting for them, ${ }^{9}$ and the sociodemographic individual and family characteristics.

It is worth noting that this study does not seek to compare the coefficients of the models in the two countries but rather to focus on the comparison of the mediation processes within the two countries. Although we made efforts to harmonize measures in the two countries, due to data limitation, the harmonization remains mostly at the conceptual level. We therefore focus on comparing the mechanisms at play rather than directly compare the magnitude of the social class gap in Scotland and the USA. This approach also allows us to consider the particularity of each education system (e.g. studied AP/IB and Honors vs. passed Highers and Advanced Highers).

\section{Results}

\section{Descriptive results}

Figure 1 shows the bivariate relationship between parental social class and access to selective universities in Scotland and the USA. In both countries, tertiary enrolment was stratified by parental social class, particularly at the top and bottom of the university grouping. For instance, while $34 \%$ of students from the service class attended an 'ancient' university, only $16 \%$ of those coming from the working class did so. While in the USA the percentages attending top universities (i.e. 'highly and most-competitive' institutions) were lower across all social classes, the gradient of social class was still marked with $16 \%$ of students from the service class attending the top universities compared to about $4 \%$ of those coming from the working class. Although there were substantial social class gaps in the access to the second most prestigious group of universities (particularly in the USA), there was little difference with respect to access to 'new' universities in Scotland, and 'non-competitive and less-competitive' universities in the USA. Finally, another wide social class gap in both countries emerged at the bottom of the hierarchy-that is, enrolment in FE/2year colleges. In Scotland, only $18 \%$ of students from the top social class entered this type of HE institutions, compared to $31 \%$ and $47 \%$ of students from the intermediate and working class respectively. In the USA, the differences ranged from $32 \%$ for those from the service class to $62 \%$ for those from the working class. Additional descriptive statistics by parental social class (i.e. mean number of advanced-level courses, average grades obtained and type of subjects) are available in Online Resource 2 (Tables A2-A3).

\footnotetext{
${ }^{9}$ M5 does not include the number of academic advanced courses. This was because it was strongly correlated with the dummies of subject type and introducing them together would have resulted in multicollinearity problems. However, type of subjects and grades were moderately correlated and when modelling them together, the average variance inflation factor (VIF) was 1.57 in Scotland and 1.35 in the USA, both below the 2.5 threshold which is usually considered as indicating potential multicollinearity.
} 


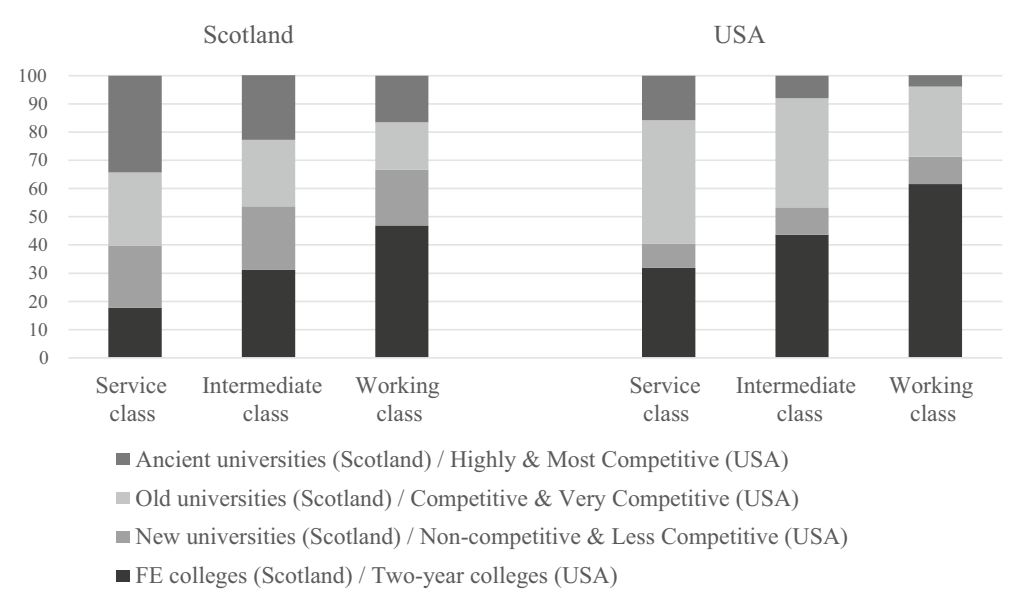

Fig. 1 Parental social class and type of HE institution attended in Scotland and the USA

\section{Multiple regression analysis}

We now turn to the models from multinomial logistic regression to test whether social class differences remain statistically significant after controlling for other background characteristics and, more importantly, after taking into account different indicators measuring the academic rigour of the secondary school curriculum. Tables 1 and 2 display only the coefficients for parental social class expressed as AMEs and how these coefficients change across different models. For the sake of simplicity, we did not report coefficients for the rest of the variables included, given that this study focuses mostly on the mediation process. However, we reported all coefficients in the electronic supplementary material, Online Resource 3.

The results for Scotland (Table 1) indicate that, after controlling for individual and family background characteristics in M1, there remain statistically significant social class differences in access to 'ancient' universities, with those from the intermediate class being 10 percentage points less likely to attend such universities and those from the working class being 17 percentage points less likely to do so compared to their counterparts from the service class. Regarding the social class gap between the intermediate and service classes, any of the academic curriculum components, namely the number of academic Highers and Advanced Highers (M2), the type of academic subjects studied at an advanced level (M3) and the grades obtained for these subjects (M4), reduced the gap to the point of no longer being statistically significant. Among the three components of academic strength, however, the type of subjects taken played the most important role in the mediation process, reducing the gap from 10 percentage points to 4 percentage points. This was followed by grades and number of Highers and Advanced Highers taken. The difference in access to 'ancient' universities between the service and working classes remained significant even when we controlled for number and grades of advanced academic subjects. Yet, this difference was reduced to 6 percentage points in M2 and 5.5 percentage points in M4, indicating that these two components of academic rigour partially explained the social class differences. Interestingly, the type of advanced academic subjects alone (M3) appeared to be more crucial in explaining the social class gap in access to 'ancient' universities, reducing the gap to 5 percentage points and which was no longer statistically significant. 
Table 1 The mediating role of the strength of school curriculum for parental class effects on access to HE institutions in Scotland

\begin{tabular}{|c|c|c|c|c|c|}
\hline & M1 & M2 & M3 & M4 & M5 \\
\hline \multicolumn{6}{|l|}{ Ancient universities } \\
\hline \multicolumn{6}{|c|}{$\begin{array}{l}\text { Parental soc. class } \\
\quad \text { (ref. cat. : Service class) }\end{array}$} \\
\hline Intermediate class & $-0.106 * * *(-3.50)$ & $-0.053 \quad(-1.92)$ & $-0.039(-1.41)$ & $-0.046 \quad(-1.67)$ & $-0.030(-1.09)$ \\
\hline Working class & $-0.162 * * *(-5.89)$ & $-0.063 *(-2.26)$ & $-0.050(-1.78)$ & $-0.055 *(-1.99)$ & $-0.034(-1.21)$ \\
\hline Unclassified & $-0.169 * \quad(-2.42)$ & $-0.067 \quad(-0.86)$ & $-0.065(-0.85)$ & $-0.084 \quad(-1.14)$ & $-0.059(-0.80)$ \\
\hline \multicolumn{6}{|l|}{ Old universities } \\
\hline \multicolumn{6}{|l|}{ Parental soc. class } \\
\hline Intermediate class & $-0.018 \quad(-0.60)$ & $-0.0003(-0.01)$ & $0.003 \quad(0.12)$ & $-0.007(-0.24)$ & $0.002(-0.06)$ \\
\hline Working class & $-0.064 *(-2.40)$ & $-0.009 \quad(-0.33)$ & $-0.016(-0.57)$ & $-0.022(-0.77)$ & $-0.023(-0.82)$ \\
\hline Unclassified & $-0.034 \quad(-0.47)$ & $(0.37)$ & $0.024 \quad(0.31)$ & $0.011 \quad(0.15)$ & $0.020 \quad(0.26)$ \\
\hline \multicolumn{6}{|l|}{ New universities } \\
\hline \multicolumn{6}{|l|}{ Parental soc. class } \\
\hline Intermediate & $0.033 \quad(1.12)$ & $0.010 \quad(0.37)$ & $-0.006(-0.21)$ & $0.001 \quad(0.05)$ & $-0.011(-0.40)$ \\
\hline Working class & $0.008 \quad(0.30)$ & $-0.0006(-0.02)$ & $-0.008(-0.29)$ & $-0.016(-0.60)$ & $-0.016(-0.60)$ \\
\hline Unclassified & $-0.050(-0.79)$ & $-0.059 \quad(-0.93)$ & $-0.074(-1.22)$ & $-0.069(-1.09)$ & $-0.077(-1.26)$ \\
\hline \multicolumn{6}{|l|}{ FE colleges } \\
\hline \multicolumn{6}{|l|}{ Parental soc. class } \\
\hline Intermediate class & $0.091 * * *(3.41)$ & $0.043 * \quad(2.12)$ & $0.042 * \quad(2.07)$ & $0.052 * \quad(2.37)$ & $0.043 * \quad(2.12)$ \\
\hline Working class & $0.218 * * *(7.83)$ & $0.073 * * *(3.73)$ & $0.073 * * *(3.79)$ & $0.093 * * *(4.55)$ & $0.072 * * *(3.80)$ \\
\hline Unclassified & $0.253 * * \quad(3.14)$ & (1.94) & $0.115^{*} \quad(2.22)$ & $0.141 * * \quad(2.68)$ & $0.116^{*} \quad(2.27)$ \\
\hline
\end{tabular}

Average marginal effects, $t$ statistics in parentheses

$M 1$ gender + ethnicity + family structure + number of siblings, $M 2 \mathrm{M} 1$ + number of academic subjects taken at Higher/Advanced Higher level, M3 M1 + type of academic subjects taken at Higher/Advance Higher level, M4 M1 + total UCAS for academic subjects taken at Higher/Advance Higher level, M5 M3 + total UCAS for academic subjects taken at Higher/Advance Higher level

$* p<0.05 ; * * p<0.01 ; * * * p<0.001$

Furthermore, regarding access to 'old' universities, a significant social class gap appeared only between the service and the working class (M1), and this was estimated to be 6 percentage points in favour of the service class. However, any of the considered components tested in M2-M4 reduced the social class gap and took away the statistical significance, with number of Highers and Advanced Highers reducing the gap to below 1 percentage point, followed by type of subjects reducing the gap to 1.6 percentage points, and grades diminishing the existing difference to 2 percentage points. Regarding access to 'new' universities, no significant differences by social class were found (M1).

Finally, with respect to entering FE colleges, a reversed association emerged with students from intermediate and working classes being more likely to study in such institutions than those from service class ( 9 and 22 percentage points difference respectively). Contrary to our previous results, none of the considered academic components fully explained this relationship. Therefore, as opposed to 'ancient' universities - where the type of advanced subjects studied in secondary school fully explained the higher probability of those from more advantaged backgrounds to access these universities - other unexplained factors beyond the 
Table 2 The mediating role of the strength of school curriculum for parental class effects on access to HE institutions in the USA

\begin{tabular}{|c|c|c|c|c|c|}
\hline & M1 & M2 & M3 & M4 & M5 \\
\hline \multicolumn{6}{|c|}{ Highly and most competitive } \\
\hline \multicolumn{6}{|c|}{$\begin{array}{l}\text { Parental soc. class } \\
\text { (ref. cat. : Service Class) }\end{array}$} \\
\hline Intermediate class & $-0.055^{* * *}(-6.77)$ & $-0.028 * * *(-3.94)$ & $-0.029 * * *(-4.05)$ & $-0.041 * * *(-5.37)$ & $-0.028 * * *(-4.02)$ \\
\hline Working class & $-0.081 * * *(-8.65)$ & $-0.041 * * *(-3.54)$ & $-0.04 * * * \quad(-3.49)$ & $-0.055 * * *(-5.15)$ & $-0.037^{* *} \quad(-3.20)$ \\
\hline Unclassified & $-0.034 \quad(-0.59)$ & $(0.35)$ & $(0.30)$ & $-0.018 \quad(-0.27)$ & 0.023 \\
\hline \multicolumn{6}{|l|}{$\begin{array}{l}\text { Competitive and very } \\
\text { competitive }\end{array}$} \\
\hline \multicolumn{6}{|l|}{ Parental soc. class } \\
\hline Intermediate class & $-0.031 * \quad(-2.14)$ & $-0.014 \quad(-1.02)$ & $-0.014 \quad(-0.97)$ & $-0.012 \quad(-0.84)$ & $-0.012 \quad(-0.88)$ \\
\hline Working class & $-0.148 * * *(-8.53)$ & $-0.102 * * *(-5.83)$ & $-0.099 * * *(-5.68)$ & $-0.1 * * *(-5.70)$ & $-0.096^{* * *}(-5.44)$ \\
\hline Unclassified & $-0.159 * \quad(-2.00)$ & $-0.132 \quad(-1.59)$ & -0.139 & $-0.138 \quad(-1.68)$ & -0.147 \\
\hline $\begin{array}{l}\text { Least competitive and } \\
\text { non-competitive }\end{array}$ & \multicolumn{4}{|c|}{ non-competitive } & \\
\hline \multicolumn{6}{|l|}{ Parental soc. class } \\
\hline Intermediate class & $0.006 \quad(0.71)$ & $0.004(0.44)$ & $0.004 \quad(0.47)$ & $0.005 \quad(0.59)$ & $0.004 \quad(0.42)$ \\
\hline Working class & $-0.008(-0.75)$ & $-0.008(-0.79)$ & $-0.009(-0.82)$ & $-0.007(-0.69)$ & $-0.009(-0.88)$ \\
\hline Unclassified & $0.096 \quad(1.30)$ & $0.088 \quad(1.23)$ & $0.089 \quad(1.25)$ & $0.094 \quad(1.27)$ & $0.085 \quad(1.22)$ \\
\hline \multicolumn{6}{|l|}{ Two-year colleges } \\
\hline \multicolumn{6}{|l|}{ Parental soc. class } \\
\hline Intermediate class & $0.08 * * * \quad(5.36)$ & $0.038 * *(2.83)$ & $0.038^{* *} \quad(2.80)$ & $0.047 * * *(3.45)$ & $0.037 * * \quad(2.72)$ \\
\hline Working class & $0.236^{* * *}(12.63)$ & $0.15^{* * * *}(8.77)$ & $0.147 * * *(8.59)$ & $0.162 * * *(9.16)$ & $0.142 * * *(8.30)$ \\
\hline Unclassified & $(1.07)$ & $0.017 \quad(0.21)$ & $(0.37)$ & $(0.71)$ & 0.039 \\
\hline
\end{tabular}

Average marginal effects, $t$ statistics in parentheses

$M 1$ gender + ethnicity + family structure + number of siblings, $M 2 \mathrm{M} 1+$ number of courses in AP/IB/Honors, M3 M1 + type of academic subjects taken in AP/IB/Hons, $M 4 \mathrm{M} 1$ + GPA in AP/IB/Hons, M5 M3 + GPA in AP/ IB/Honors

$* p<0.05 ; * * p<0.01 ; * * * p<0.001$

less stringent academic curriculum studied at school increase the probability of those from less advantaged backgrounds to enter FE colleges. These unexplained factors might be related to student preferences for shorter and more vocationally oriented educational paths leading to clearer labour market outcomes or proximity of the FE college to a student's home (Gallacher 2009). Table 2 shows the corresponding results for the USA. Regarding the most selective institutions, the 'highly and most competitive' students from both intermediate and working classes were significantly less likely to enter these institutions, with the former showing a 5.5percentage point lower chance and the latter a 8.1-percentage point lower chance. The number of advanced academic courses (M2) and the type of subject taken (M3) reduced these social class differences to 2.9 percentage points for the intermediate class and 4 percentage points for the working class, a slightly larger reduction compared to the reduction in the social class gap when we included the GPA in advanced courses (M4).

Also, we found significant social class differences in access to the second most prestigious group of universities, the 'competitive and very competitive' category. The probabilities of 
students from the intermediate and working classes were 3.1 percentage points and 14.8 percentage points lower in entering these institutions (M1) compared to their peers from the service class. ${ }^{10}$ The difference between the service and intermediate classes was no longer statistically significant when controlling for any of the components of academic strength separately in M2-M4 and together in M5. Therefore, the academic strength of curriculum explained the social class differences in this case. However, a significant difference in accessing the 'competitive and very competitive' universities remained between the service and working classes throughout the models (M2-M5). The three academic components reduced the social class gap to 9.9-10.2 percentage points when each of these factors was included separately, and to 9.6 percentage points when they were included together. This suggests that other factors beyond the academic strength of the curriculum and the obtained grades in these courses are responsible for these differences.

Although we did not find significant social class difference in access to 'non- and less competitive' institutions, we report a reverse association (that is, a positive association for the least-advantaged group), as in the Scottish case, when considering entry to 2-year colleges. Students from the intermediate class showed an 8-percentage point higher probability of entering these types of colleges than those from the service class. About half of the gap was explained equally by number (M2) and type of advanced academic courses taken (M3) and slightly less than half by the GPA in advanced courses (M4). When taking into account type of subjects and grades together (M5), students from the intermediate class were still 3.7 percentage points more likely to be enrolled in these colleges. Moreover, students from the working class showed a 23.6-percentage point higher probability in enrolling at a 2-year college over their service class counterparts. Although the number (M2) and the type of subjects taken (M3) accounted for some of this difference, a gap of about 15 percentage points remained. Grades explained slightly less of this difference, leaving an unexplained gap of 16.2 percentage points. When accounting for both the type of subjects and grades (M5), we noticed a further reduction, but a large difference of 14.2 percentage points remained unexplained. Therefore, in both countries, academic strength was more important in explaining social inequalities in access to more selective universities and weaker in explaining the inequalities in entering FE colleges/2year colleges, hence the importance of providing a disaggregated picture by the selectivity of university instead of simply contrasting access to degree versus sub-degree programmes.

\section{Conclusion}

This study has provided new insights on the importance of national factors related to school curricula and status of institutions in the reproduction of social inequalities in HE. A key objective of our study was to investigate the relative importance of different components of the academic strength of secondary school curriculum (i.e. the number, type of subjects and grades of advanced courses) in explaining social class differences in entering selective HE institutions. We focused

\footnotetext{
${ }^{10}$ While the social class difference in the probability of entering 'competitive and very competitive' universities between students from service and working classes appeared stronger compared to the same difference in entering 'highly and most competitive' universities, we should keep in mind that the AMEs are differences in the absolute probabilities and are therefore influenced by the overall magnitude of the absolute probabilities. In this case, the smaller difference in the first group of universities is driven by a smaller overall probability in entering these universities. Relative differences (e.g. odds ratios) do not show a stronger social class gap in entering the second group of universities compared to the first group.
} 
our attention on Scotland and the USA to uncover how commonalities and differences of the two education systems may shape young people's chances of entering prestigious HE institutions. Our results show pronounced social class gaps in entering the top HE institutions in both countries ('ancient' universities in Scotland and 'highly and most competitive' universities in the USA) with those from intermediate and working classes being less likely to enrol in such institutions. We find similar results with respect to access to the second prestigious universities ('old' universities in Scotland and 'competitive and very competitive' universities in the USA); but at least in Scotland, differences hold only for those from the working class. However, we find little evidence of social class differences in entering the third group in our ranking ('new' universities in Scotland and 'non- and less competitive' universities in the USA). Nevertheless, this study show substantive social class differences in enrolment in FE colleges in Scotland and 2-year colleges in the USA. These institutions mostly gather young people from the intermediate and working classes as compared to those from the service class.

Our results showed that in Scotland, the type of subjects studied in secondary school had the strongest role in mediating social class differences in entering 'ancient' universities, stronger than the number of Highers/Advanced Highers studied and the obtained grades for these courses. Accounting for type of subjects not only reduced social class differences substantially but also reduced the gap to the point of no longer being statistically significant. This was not the case when accounting for the other two academic components. However, with respect to the 'highly and most competitive' universities in the USA, the mediating effect of number of advanced courses studied and type of subjects studied was very similar and stronger than the GPA in advanced courses. Yet, given that the way we measured the type of subjects indirectly incorporates the number of subject taken, the fact that the type of subjects does not explain social class differences more than the number of subjects leads us to attribute a stronger relative importance to the number of subjects taken compared to the type of subjects in the USA. This can be understood considering that students in the USA enter university without choosing a college major. Conversely, in Scotland, where students apply for both a university and a major - and top universities express a preference for certain facilitating subjects - type of subjects taken has a more important role in explaining the existing social class differences. Regarding access to the second group of universities, the three curriculum components played a similar role in explaining social class differences in both Scotland and the USA. Finally, in both countries, the number of advanced courses taken in secondary school explained a larger part of the relationship between social class and enrolment in a FE/2-year college. This was followed closely by the obtained grades in these courses.

Our study also tested whether the strength of academic curriculum based on all three measures fully explain social class differences in access to selective universities. Based on our results, we can answer positively to this question only for Scotland. In the USA, a considerable gap remains even after accounting for variations among students from different social classes in the strength of academic curriculum studied. Since university attendance involves high costs, which are often commensurate to the prestige of the university, this remaining gap in the USA could be related to differences in parental economic resources. Moreover, other types of parental support and resources, such as parents' ability to help with more subjective parts of the university application such as the statement of intent, recommendation letters and extracurricular activities - which are highly valued in the admission process at US top universities admission - all are likely to play a stronger role in the USA than in Scotland. Finally, our results showed that substantive social class differences in entry to the less prestigious $\mathrm{HE}$ institutions remain in both Scotland and the USA, even after controlling for differences in the 
school curriculum. This might be related to preferences of students from less advantaged social classes for more vocational educational paths with a faster stream into the labour market.

Taken together, the findings of our study illustrate that the ways in which inequalities in access to selective universities are shaped depend on the characteristics of the education system. Social stratification patterns across HE institutions are similar in the USA and Scotland, but the mechanisms by which these patterns are produced reflect national institutional contexts. Thus, social inequalities in entry to the most prestigious universities are mediated by different dimensions of strength of curricula in the two countries: quantity of advanced academic courses taken in the USA and types of courses in Scotland. Moreover, in the USA, social origin factors have a direct effect, not mediated by school achievement and curricula, on entry to prestigious universities. This is also likely to be linked to the feature of the USA HE system where economic factors may play a larger role than in Scotland.

Acknowledgments This research draws on research that is being conducted as part of the 'Education and Social Stratification' research strand in the Applied Quantitative Methods Network (AQMeN) Centre funded by the ESRC (Grant reference: ES/K006460/1).

Open Access This article is distributed under the terms of the Creative Commons Attribution 4.0 International License (http://creativecommons.org/licenses/by/4.0/), which permits unrestricted use, distribution, and reproduction in any medium, provided you give appropriate credit to the original author(s) and the source, provide a link to the Creative Commons license, and indicate if changes were made.

\section{References}

Allmendinger, J. (1989). Educational systems and labor market outcomes. European Sociological Review, 5 , $231-250$

Alon, S., \& Tienda, M. (2007). Diversity, opportunity, and the shifting meritocracy in higher education. American Sociological Review, 72, 487-511.

An, B. P. (2010). The relations between race, family characteristics, and where students apply to college. Social Science Research, 39, 310-323.

Arum, R., Gamoran, A., \& Shavit, Y. (2007). More inclusion than diversion: expansion, differentiation, and market structure in higher education. In Y. Shavit, R. Arum, \& A. Gamoran (Eds.), Stratification in higher education: a comparative study (pp. 1-35). Stanford: Stanford University Press.

Barron's Educational Series. (2002). Profiles of American colleges, 25th edition 2003. Hauppauge: Barron's Educational Series, Inc..

Bastedo, M. N., \& Jaquette, O. (2011). Running in place: low-income students and the dynamics of higher education stratification. Educational Evaluation and Policy Analysis, 33, 318-339.

Boliver, V. (2013). How fair is access to more prestigious UK universities? British Journal of Sociology, 64, 344 364.

Brand, J. E., \& Halaby, C. N. (2006). Regression and matching estimates of the effects of elite college attendance on educational and career achievement. Social Science Research, 35, 749-770.

Clinedinst, M. E. (2015). State of college admission: 2014. Alexandria: National Association for College Admission Counseling.

College Board. (2016). AP Students: AP Courses. Retrieved from https://apstudent.collegeboard.org/apcourse.

Erikson, R. (1984). Social class of men, women and families. Sociology, 18, 500-514.

Gallacher, J. (2009). Higher education in Scotland's colleges: a distinctive tradition? Higher Education Quarterly, 63, 384401.

Gerber, T. P., \& Cheung, S. Y. (2008). Horizontal stratification in postsecondary education: forms, explanations, and implications. Annual Review of Sociology, 34, 299-318.

Handwerk, P., Tognatta, N., Coley, R. J., \& Gitomer, D. H. (2008). Access to success: patterns of advanced placement participation in us high schools. Princeton: Educational Testing Service.

Iannelli, C., Gamoran, A., \& Paterson, L. (2011). Scottish higher education, 1987-2001: expansion through diversion. Oxford Review of Education, 37, 717741. 
Iannelli, C., Smyth, E., \& Klein, M. (2016). Curriculum differentiation and social inequality in higher education entry in Scotland and Ireland. British Educational Research Journal, 42, 561-581.

Integrated Postsecondary Education Data System. (2014). Complete Data Files. Retrieved from http://nces.ed. gov/ipeds/datacenter/DataFiles.aspx.

Jacob, M., Klein, M., \& Iannelli, C. (2015). The impact of social origin on graduates' early occupational destinations - an Anglo German comparison. European Sociological Review, 31, 460-476.

Jerrim, J., Chmielewski, A. K., \& Parker, P. (2015). Socioeconomic inequality in access to high-status colleges: a cross-country comparison. Research in Social Stratification and Mobility, 42, 20-32.

Johnson, J., \& Hayward, G. (2008). Expert group report for award seeking admission to the UCAS tariff: Scottish Highers and Advanced Highers. Cheltenham: UCAS.

Kerckhoff, A. C. (2001). Education and social stratification processes in comparative perspective. Sociology of Education, 74, 3-18.

Klugman, J. (2013). The Advanced Placement arms race and the reproduction of educational inequality. Teachers College Record, 115.

Lareau, A. (2011). Unequal childhoods: class, race, and family life (2nd ed.). Berkeley: University of California Press.

Lucas, S. R. (2001). Effectively maintained inequality: education transitions, track mobility, and social background effects. American Journal of Sociology, 106, 1642-1690.

Massey, D. S., Charles, C. Z., Lundy, G., \& Fischer, M. J. (2003). The source of the river: the social origins of freshmen at America's selective colleges and universities. Princeton: Princeton University Press.

Mood, C. (2010). Logistic regression: why we cannot do what we think we can do, and what we can do about it. European Sociological Review, 26, 67-82.

Radford, A. W. (2013). Top student, top school?: how social class shapes where valedictorians go to college. Chicago: University of Chicago Press.

Reay, D., David, M. E., \& Ball, S. (2005). Degrees of choice: class, race, gender and higher education. Sterling: Trentham Books.

Roksa, J., Grodsky, E., Arum, R., \& Gamoran, A. (2007). United States: changes in higher education and social stratification. In Y. Shavit, R. Arum, \& A. Gamoran (Eds.), Stratification in higher education: a comparative study (pp. 165-191). Stanford: Stanford University Press.

Rose, D., \& Harrison, E. (2010). Social class in Europe: an introduction to the European socio-economic classification. New York: Routledge.

Russell Group. (2016). Informed Choices. United Kingdom. Retrieved from http://russellgroup.ac.uk/media/5320 /informedchoices.pdf.

Schührer, S., Carbonaro, W., \& Grodsky, E. (2016). Reproduction of inequality in educational attainment through curricular differentiation in secondary school-a case study of the USA. In H.-P. Blossfeld, S. Buchholz, J. Skopek, \& M. Triventi (Eds.), Models of secondary education and social inequality: an international comparison (pp. 249-268). Northampton: Edward Elgar Publishing, Inc..

Shavit, Y., Arum, R., \& Gamoran, A. (2007). Stratification in higher education: a comparative study. Stanford: Stanford University Press.

Sullivan, A., Parsons, S., Wiggins, R., Heath, A., \& Green, F. (2014). Social origins, school type and higher education destinations. Oxford Review of Education, 40, 739-763.

Turner, R. H. (1960). Sponsored and contest mobility and the school system. American Sociological Review, 25 , $855-867$. 